\title{
A PRÁTICA DO CONTROL+C CONTROL+V EM TEXTOS PRODUZIDOS NA UNIVERSIDADE: COMO FICA A PRODUÇÃO DO CONHECIMENTO?
}

\section{THE PRACTICE OF CONTROL+C CONTROL+V IN TEXTS PRODUCED AT THE UNIVERSITY: HOW IS THE PRODUCTION OF KNOWLEDGE?}

\author{
Maria Beatriz de Souza Almeida Delduque*
}

\begin{abstract}
RESUMO: Esta pesquisa tem como objetivo analisar a prática do Control+c- Control+v na produção escrita de dois relatórios de aulas práticas da disciplina de Microbiologia por estudantes do segundo período do Curso de Engenharia Agronômica de uma instituição privada. A justificativa para o estudo é a necessidade de problematizar o plágio como prática a ser evitada, pois não contribui no processo de construção de conhecimentos sobre a escrita. Caracteriza-se como uma pesquisa qualitativa e indiciária. Para a análise dos relatórios nos baseamos em autores como Lima e Amorim (2014), Fabiano (2014), Grigoletto (2013), Barzotto (2016), Possenti (2002), Fabiano (2014), dentre outros Os resultados apontam: que os relatórios produzidos apresentaram uma escrita que ora tentava omitir o plágio, com alterações mínimas, ora o evidenciava com cópias íntegras, sem referências; que as produções evidenciaram uma escrita onde o apagamento do autor (aluno) deu-se em todo o texto, demonstrando um sujeito que não se compromete com o próprio processo de construção de conhecimentos; que a cópia se volta contra o próprio profissional em formação, pois, ao não se posicionar frente ao saber, não se responsabilizando por aquilo que pronuncia, perdendo a oportunidade de desenvolver uma escrita que mobiliza, que considera a importância da negociação de sentidos, demonstrando uma percepção ingênua de que para tudo o que se tem a dizer existe de antemão uma expressão (palavra) pronta e disponível no contexto na internet.
\end{abstract}

Palavras-chave: Produção escrita; Plágio; Apagamento de autoria.

ABSTRACT: This research aims to analyze the practice of Control+c-Control+v in the production of written reports of practical classes in the discipline of Microbiology by students from the second term of the Agronomic Engineering Course of a private institution. The justification for the study is the need to discuss plagiarism as a practice to be avoided, as it does not contribute to the process of knowledge building about writing. It is characterized as qualitative and indicative. For the analysis of the reports, we based on authors such as Lima and Amorim (2014), Fabiano (2014), Grigoletto

\footnotetext{
"Mestra em Educação pela Universidade Federal do Triângulo Mineiro (UFTM). Professora de Leitura e Produção de textos e de língua espanhola do curso de Letras Português/Espanhol e Secretariado Executivo da Universidade de Uberaba (Uniube).
} 
(2013), Barzotto (2016), Possenti (2002), Fabiano (2014), among others The results point out: that the reports produced presented writing that sometimes tried to omit plagiarism, with minimal changes, sometimes evidenced it with full copies, without references; that the productions evidenced writing where the deletion of the author (student) occurred throughout the text, demonstrating a subject who is not committed to the process of knowledge construction itself; that the copy turns against the professional in training, because by not taking a stand in the face of knowledge, not taking responsibility for what he pronounces, losing the opportunity to develop writing that mobilizes, which considers the importance of negotiating meanings, demonstrating a naive perception that for everything that has to be said there is an expression (word) ready and available in the context of the internet beforehand.

Keywords: Written production; Plagiarism; Authorship deletion.

\section{INTRODUÇÃO}

A produção escrita é um tema muito discutido atualmente, principalmente com relação à questão do plágio, um assunto presente no contexto educacional, mesmo sendo uma prática condenada por todos os níveis de ensino, é algo recorrente, praticado por estudantes no Brasil e no mundo.

A expansão do uso das tecnologias propicia o acesso à múltiplas fontes de informação, os estudantes têm acesso a trabalhos e produções acadêmicas dos mais variados assuntos, e, mesmo sabendo que o plágio é condenável, considerado um crime, copiam trabalhos por inteiro ou fragmentados para fazer do texto de outrem o seu.

Isso ocorre pela facilidade no acesso ao conhecimento já produzido. Para Lima e Amorim (2014, p. 167), "o conhecimento se oferece em sites de busca da internet, a exemplo do google, a partir de um simples "clic". Mesmo sendo uma potente ferramenta, quase imprescindível atualmente, os efeitos promovidos pelo espaço cibernético podem ser indesejáveis", a cópia é um deles. Por isso, a discussão é relevante, no sentido de propiciar uma reflexão acerca do tema, pois, ao plagiar, o aluno perde a oportunidade de construir seu conhecimento para produzir novos saberes.

Nessa perspectiva, o presente artigo traz um recorte da dissertação de mestrado, intitulada "A (Des) Construção dos Processos de Leitura e Escrita de Acadêmicos em Cursos de Engenharia Agronômica e de Produção", em 
Delduque (2017), que objetivou analisar em quais condições as produções escritas produzidas por discentes da área de Engenharia de Produção e Agronômica adquiriam o estatuto de produção de conhecimento.

Nesta pesquisa maior, foram selecionados nove relatórios de aula prática de Microbiologia do curso de Engenharia agronômica. Deste total, dois serão analisados neste artigo.

O artigo encontra-se organizado da seguinte maneira: discussão teórica, com reflexões sobre a escrita nas engenharias, A seguir, apresentamos o percurso teórico-metodológico para realização do estudo, as análises das produções escritas Relatórios de uma aula prática de Microbiologia, denominados (RAP1 e RAP2) e, para finalizar, as conclusões a que chegamos a partir da pesquisa.

\section{REFERENCIAL TEÓRICO}

\section{A escrita nas engenharias}

Existe 0 estereótipo adotado por muitos profissionais da área das engenharias de que o engenheiro não deve preocupar-se com a escrita, pois o mais importante são os conhecimentos técnicos, principalmente os advindos das exatas, precisamente o saber calcular.

No entanto, a produção escrita é uma competência comunicativa que possivelmente atenderá às demandas específicas da área profissional, que possui marcadamente rotinas comunicacionais específicas da área de atuação nos seus contextos de formação, de trabalho, enfim, nas suas especificidades comunicativas.

Bazzo e Pereira (2009) ressaltam que tanto engenheiros em formação, quanto professores em cursos de engenharia consideram que alguns estudantes, não julgam relevante levar a sério a prática da escrita, deixando-a em segundo plano. Essa é uma atitude equivocada, pois a atuação do engenheiro, de acordo com os referidos autores, requer boa comunicação, já que no dia a dia esses profissionais precisam comunicar-se usando a escrita 
inerente ao seu trabalho, visto que o engenheiro expede ordens aos seus subordinados nas hierarquias das empresas, realiza projetos para clientes e também para órgãos financiadores, elabora relatórios para a direção da empresa, prepara manuais de utilização de produtos, precisa divulgar seus trabalhos e pesquisas em eventos científicos como congressos, seminários, dentre outros, além de publicá-los em revistas técnicas e periódicos da área. Assim sendo, o engenheiro precisa dar importância à habilidade escrita, pois o profissional não é só aquele que calcula, projeta e decide. Suas atribuições vão além, pois ao calcular, projetar e transformar em projeto para torná-lo real, o engenheiro deve expressar-se, fazer-se compreender para viabilizar seus projetos e ações.

De acordo com Bazzo e Pereira (2009), a linguagem técnica nas engenharias deve ser:

Simples, clara, precisa e, tanto quanto possível, vazada em frases curtas. Não devemos recorrer a imagens literárias, metáforas poéticas ou outro recurso retórico similar a estes, pois cada palavra deve ser empregada no seu sentido direto, sem dar margem a segundas interpretações. Quando usamos esses recursos, embora o texto fique aparentemente mais elegante e pareça exprimir erudição do escritor, pode confundir o registro de ideias técnicas. [...] Deve também ser baseada em dados objetivos e verificados, a partir dos quais analisa, sintetiza, argumenta e conclui (BAZZO; PEREIRA 2009, p. 47-49).

Esse uso que os engenheiros fazem da linguagem, pensando-a de forma objetiva para fins específicos, remete à reflexão de Bakhtin (2003, p. 261) ao afirmar que "os diversos campos da atividade humana estão ligados ao uso da linguagem", a partir de enunciados orais ou escritos, dadas as finalidades, o conteúdo temático, o estilo de linguagem, a estrutura composicional e a seleção de recursos lexicais, fraseológicos e gramaticais

Bakhtin (2003, p. 262) ressaltou que:

O conteúdo temático, o estilo, a construção composicional, estão indissoluvelmente ligados no todo do enunciado e são igualmente determinados pela especificidade de um determinado campo da comunicação. Evidentemente, cada enunciado particular é individual, mas cada campo de utilização da língua elabora seus tipos relativamente estáveis de enunciados, os quais denominamos gêneros do discurso. 
Não é objetivo deste estudo tratar dos gêneros do discurso, mas consideramos importante mencionar, pois eles circulam na esfera de trabalho dos engenheiros, a partir de uma linguagem técnica. Essa linguagem, de acordo com Bazzo e Pereira (2009), é muito valorizada. Na área das Engenharias, a redação técnica é priorizada, elaborada em um estilo impessoal, objetivo, modesto, cortês e claro, com textos em terceira pessoa, evitando-se a expressões como: "meu trabalho", "minhas conclusões", substituindo-as por "o presente trabalho", "conclui-se que". Conforme Bazzo e Pereira (2009) apontaram, essa forma de comunicar-se pode ser contestada por autores que consideram que essa impessoalidade, de certa forma, pretende isentar o autor da responsabilidade do que afirma ou declara, sendo a mais indicada para textos técnicos. Entretanto, a neutralidade linguística não consegue garantir a isenção de responsabilidade.

Bazzo e Pereira (2009, p. 49) ressaltaram que é preciso ser cortês e claro, já que a clareza de ideias é um grande facilitador da comunicação. Para ser claro, é preciso conhecer o vocabulário técnico e, para tanto, é necessário a leitura frequente de dicionários e informações especializadas. $O$ importante para os engenheiros é que se comuniquem e se façam compreendidos. Todavia, os autores ressaltam o equívoco desses profissionais que, muitas vezes, relegam a segundo plano a escrita, por acreditar que não é tão importante como o conhecimento de cálculo. De acordo com Bazzo e Pereira (2009):

\footnotetext{
Não é raro ouvir profissionais da área cometerem o equívoco de afirmar que, por serem engenheiros, não sabe ou não precisam saber escrever ou falar corretamente. Ledo engano! Não são poucas as oportunidades em que a capacidade de comunicação, tanto oral quanto escrita, é indispensável. As necessidades cotidianas de participar de seminários, congressos, mesas redondas, entrevistas (BAZZO; PEREIRA, 2009, p. 94).
}

Ao participarem de seminários, congressos e mesas redondas em eventos de sua área, os engenheiros precisam mostrar suas produções, e produzir conhecimento sobre o objeto da escrita nas engenharias, vai além de usar uma linguagem técnica, pronto e disponível, requer compreender dados, 
processá-los, analisá-los, para que eles façam sentido e se tornem informações e a partir delas produzir o conhecimento, compreendendo teorias a partir das leituras realizadas, atribuindo significados, sentidos, para a partir disso, produzir conhecimento, sendo capaz de empreender o novo a partir do que já se tem, conhece e compreende.

A engenharia no mundo contemporâneo, para Loder (2007, p. 01):

É um campo de conhecimento reconhecido pela sociedade como instância de solução de problemas encontrados nas mais diferentes áreas e atividades da vida cotidiana como, por exemplo: transporte, habitação, alimentação, energia e comunicações.

Ao trabalhar na resolução de problemas, o engenheiro produz conhecimento e pauta suas ações a partir dos impactos sociais, ambientais, econômicos e técnicos que essas soluções geram. Nesse sentido, a escrita deveria ser trabalhada nesses cursos de forma mais mobilizadora, o que requer também leituras que mobilizem. De acordo com Grigoletto (2011, p. 94) elas são as que "mexem com a ordenação sem falhas do texto do texto, deslocando sentidos", para a autora é preciso promover no ensino superior "leituras que desloquem sentidos e proponham outras interpretações, em oposição a leituras definitivas, que não deixam espaço à contribuição do leitor".

Os cursos de Engenharia Agronômica, tanto de instituições públicas de ensino superior, quanto privadas, oferecem aos estudantes em formação a disciplina de Metodologia Científica, que se propõe:

\footnotetext{
Discutir os diferentes tipos de conhecimento; participar aos acadêmicos referencial técnico-prático para a elaboração de um projeto científico em Agronomia destacando a sua importância como pesquisador. Demonstrar as etapas para o desenvolvimento do trabalho acadêmico. Apresentar as etapas de elaboração de um projeto de pesquisa. Acompanhar a elaboração de um projeto de pesquisa (BRASIL, 2014, p.47).
}

Essa disciplina tem como objetivo orientar os engenheiros em formação no conhecimento sobre os pressupostos teóricos que fundamentam métodos, modelos e técnicas de síntese, análise e inferências, buscando formas adequadas para a apresentação de pesquisas científicas. $O$ foco de leitura dessa disciplina é a análise e discussões de textos técnicos e científicos da 
área, inviabilizando uma discussão mais profunda com os estudantes acerca do uso da linguagem nos mais variados contextos acadêmicos profissionais, culturais, entre outros.

Fabiano (2014) realizou uma crítica em relação ao discurso da universidade para propiciar o ensino, apontando que:

O discurso da universidade é o da inculcação e, por isso, nem sempre os alunos conseguem entender o funcionamento do curso, disciplinas, e até entender mesmo os conteúdos, que são ministrados por meio dos componentes curriculares. Na maioria das vezes, os conteúdos se transformam em um saber transmitido de forma técnica e que não atingem em termos de construção de conhecimento e de domínio teórico (FABIANO, 2014, p.231).

Exploram-se modelos de como deve ser um trabalho acadêmico, mas pensando no resultado e não no processo de produção. Quando mencionamos processo, estamos nos referindo à prática da escrita, na qual o estudante constrói seu conhecimento, com e na escrita, em seu trabalho com a linguagem, compondo sentidos na construção do seu saber, pois quando ele segue um modelo de escrita pré-estabelecido, ele perde a oportunidade de lidar com a própria escrita.

Nesse modelo que mencionamos anteriormente, o estudante aprende um vocabulário específico, reforça-se a importância da impessoalidade no texto, do discurso de autoridade (autores que são considerados autoridades no assunto), de como se deve citá-los. Trata-se da aquisição de um vocabulário específico para que aluno possa escrever, mas a reflexão sobre esse modelo, esse vocabulário, a forma de se trabalhar o texto, não é discutida. Ou seja, a escrita de um artigo científico ou de um Trabalho de Conclusão de Curso (TCC) é direcionada a partir de modelos pré-estabelecidos. Isso nos remete ao discurso de poder, que se coloca do lado do saber consagrado, inquestionável, a ser reproduzido e não oferece espaço para a autoria. Para Grigoletto (2013, p. 104):

A dificuldade da escrita própria está, então, no cerne do próprio sistema, que num mesmo movimento, produz o sujeito pela escrita e o exclui da escrita, pela sacralidade dessa prática e pela hierarquização dos sujeitos. Aos alunos, costuma-se reservar o papel 
de escribas, copiadores de outras ideias, num processo em que o conhecimento deixe de ser construído para ser reproduzido (GRIGOLETTO, 2013, p. 104).

E essa reprodução não viabiliza a possibilidade de o estudante aprender como se faz, de identificar como funciona a ordem desse discurso, e de alguma forma ressignificá-lo, ainda que comentando o que o discurso de autoridade retrata.

Ao discutir a escrita na universidade, Machado Neto (2007) afirmou que os escritos acadêmico-científicos são, cada vez mais, regulados por normas, modelos, regras e padrões, apresentados tanto para alunos, quanto para professores nas instituições de ensino. Esses escritos, de acordo com a referida autora, nascem a partir da consulta a manuais que, raras vezes, apresentam dimensões da criação, da criatividade, da autonomia e da autoria na construção do conhecimento. O mais comum é apresentarem uma dimensão utilitária, pragmática, técnica e instrumental do como fazer (escrever).

Como fica a autoria em produções acadêmicas?

Um dos maiores desafios, para Grigoletto (2011), é conferir ao aluno o direito de criar, ainda que existam regras instituídas:

\begin{abstract}
Dentre os muitos desafios que a escrita acadêmica apresenta àqueles que aceitam penetrar nesse universo, um deles é encontrar a justa medida entre o respeito aos "mestres" - as teorias, os autores estudados, as normas e convenções institucionais e de gênero, o orientador, no caso de pesquisas em formação - e uma inscrição subjetiva consequente com 0 texto produzido: uma dissertação ou tese, uma monografia, um artigo, um livro (GRIGOLETTO, 2011, p. 91).
\end{abstract}

As dificuldades dos estudantes em sua escrita, no ensino superior, parecem, como apontado por Grigoletto (2011), achar a justa medida com relação às citações de autores e, ao mesmo tempo, implicar-se com o saber que deve ser exposto no trabalho, além de dialogar com o discurso do outro e, a partir desse diálogo, criar algo singular, de modo que o aluno possa tornar-se 
autor. Quando nos referimos à autoria, consideramos importante destacar a singularidade. Sobre essa questão, Possenti (2002) afirma que:

\begin{abstract}
[...] como condição mínima, diria que é impossível pensar nesta noção de autor sem considerar de alguma forma a noção de singularidade [...]. De alguma forma, pode-se dizer que os conceitos levados em conta para conferir alguma substância a essa noção exatamente para objetivá-la de alguma forma - tem a ver com os conceitos de locutor (expressão que designa o "falante" enquanto responsável pelo que diz) e com o de singularidade (na medida em que, de algum modo, serve para chamar a atenção para uma forma um tanto peculiar de o autor estar presente no texto) [...] (POSSENTI, 2002, p. 112-113).
\end{abstract}

. Para Possenti (2002), alguém se torna autor quando consegue dar voz ao outro. Quando o autor menciona dar voz ao outro, não quer dizer que o outro não tenha voz, que não possa falar por si próprio, mas, no sentido de que, aquele que escreve, ao mencionar as leituras que realizou, precisa fazê-lo de forma crítica e reflexiva.

A universidade deve promover "a possibilidade de autoria, enquanto produção de sentidos e não como reprodutora da impossibilidade da criatividade espontânea, romântica e idealizada, fruto da inspiração divina" (SOUZA, 1999, p. 140), pois escrever é um processo muito particular, portanto subjetivo e heterogêneo, que implica desencadear 'outras ideias' e 'novos sentidos', promover abertura e deslocamento [...] (GALLI, 2010, p. 56). Nesse sentido, concordamos com a reflexão de Grigoletto (2013) que ressaltou que é preciso propiciar ao estudante, condições de desenvolvimento do 'idioma pessoal' na escrita, o direito de construir o novo, de retrabalhar textos, reconstruir sentidos, posicionar-se em relação ao conteúdo apresentado.

Grigoletto (2013) exemplificou essa visão do novo tomando como base os textos lidos pelos alunos, para a elaboração de um trabalho acadêmico. Nesse caso, o texto será retrabalhado e disso emergirão novas relações e um ponto de vista particular sobre o tema, que nem sempre estará de acordo com o autor que serviu de base para a nova produção.

Nessa concepção, a escrita se apresenta como uma prática que conduz à constituição de um sujeito de conhecimento, que se apodera da linguagem não somente para atender uma demanda acadêmica de uma determinada 
disciplina, mas para interagir com o mundo, na busca constante pelo conhecimento.

Nessa perspectiva, Almeida (2011) defendeu que é fundamental que o estudante assuma uma posição enunciativa própria, que seja capaz de posicionar-se em relação às ideias tratadas nos textos lidos, de dizer o que apreendeu dessas leituras, se concorda ou não com os pontos de vista apresentados. E isso não quer dizer anular o discurso do outro porque, na construção do conhecimento, nossos discursos (escritos ou orais) são constituídos a partir do discurso do outro, ou seja, sempre fará referência ao outro.

Barzotto e Almeida (2013) afirmam que existe, antes de um texto, uma escrita que o gerou e, antes dessa escrita, uma ou várias leituras que se articularam nesse processo. Essa articulação remete a um processo de interação entre o autor e o leitor, resultando em uma escrita com foco nessa interação. Quando o estudante produz seus textos, embora seja a sua visão sobre um determinado tema, esta produção é permeada pelos discursos dos outros. Grigoletto (2011) ressaltou que o novo não está em dizer algo que nunca foi dito, mas, sim, em uma reconfiguração de ditos anteriores. Essa reconfiguração se dá por meio da leitura.

Nesse sentido, Bakhtin (2004, p. 123) ressaltou que "o discurso escrito é, de certa maneira, parte integrante de uma discussão ideológica em grande escala: quem produz um texto responde a algo, refuta, confirma, antecipa as respostas e objeções potenciais, procura apoio etc.

Para Galli (2010, p. 51), "o processo da escrita se configura como um trabalho de incertezas, conflitos e tensões, que tende a se abrir, deslizar, (des)locar, em um movimento de (re)construção das muitas vozes e dos muitos sentidos", o que requer do estudante esforço e certa dedicação que a maioria talvez não queira empreender.

Riolfi (2011) salientou que o ato de escrever pode se constituir em um importante dispositivo de transformação da relação do sujeito com o saber, mas isso só será possível se aquele que escreve estiver disposto a se perder para depois se encontrar em seu próprio texto. Encontrar-se, em sua escrita, 
implica envolver-se com a escrita do outro por meio das leituras. Esse discurso escrito presente nas leituras do estudante é muito importante porque, nesse trabalho de (des) construção, o aprendiz se perde e se encontra em um emaranhado de vozes, tensões e conflitos que podem levá-lo a revolucionar seu interior, buscando meios que o conduzam à construção de conhecimento por meio da escrita, a partir das leituras realizadas. Mas o que observamos em muitas produções acadêmicas do ensino superior é o plágio, praticado pelos estudantes de maneira consciente. Estudantes que não refletem sobre o conteúdo para depois produzir sua escrita, preferem copiar o que já está pronto na internet, sem referenciar quem o escreveu, silenciando o autor, produzindo uma escrita com base na cópia, que não contribui em nada para a sua aprendizagem.

Essa prática do plágio, no atual contexto, tem se intensificado com o uso da tecnologia, computadores, celulares, conectados à internet, onde estudantes copiam trabalhos disponibilizados em sites da internet, sem 0 menor pudor, o que denominamos nesse estudo da prática do Control+c Control+v. Lima e Amorim ressaltam que:

\footnotetext{
$O$ acesso à informação e o modo como ela sai da internet para o papel transcorre na maioria das vezes, pelo que aqui chamamos de ritual escolar do ctrl+c (copiar) e ctrl+v (colar). Em tarefas e trabalhos acadêmicos, esse ritual responde por um nome que, nos dias atuais, é símbolo de desordem cientifica e moral: plágio (LIMA; AMORIM, 2014, p. 167).
}

A Fundação de Amparo à Pesquisa do Estado de São Paulo (2012, p.25) publicou um documento intitulado Código de Boas Práticas Científicas, definindo o plágio como "a utilização de ideias ou formulações verbais, orais ou escritas de outrem sem dar-lhe por elas, expressa e claramente, o devido crédito, de modo a gerar razoavelmente a percepção de que sejam ideias ou formulações de autoria própria”. O plágio é considerado crime, prática que deve ser rechaçada pela comunidade acadêmica em todos os níveis de ensino.

Em contrapartida, Grigoletto (2013, p. 104) salientou que "aos alunos, costuma-se reservar o papel de escribas, copiadores de outras ideias, em um processo em que o conhecimento deixa de ser construído para ser reproduzido 
A autora salienta que é preciso opor-se à essa escrita que engessa, assumindo uma concepção de escrita que mobiliza, que faz com que aquele que escreve se envolva com a escrita que resulta em autoria. Essa forma de trabalhar a escrita:

[...] resulta da implicação daquele que escreve com o saber, e, precisamente porque assume essa posição frente ao saber, bastante distinta da posição de reprodução, revela um autor que se implica subjetivamente no texto. Essa escrita mobiliza os textos lidos e as teorias estudadas de modo a compor novos mosaicos, novas configurações de sentido no interior do trabalho de análise e reflexão de uma pesquisa. E, sobretudo, essa escrita não se intimida com a falta e a incompletude inevitáveis do texto; ao contrário, é porque reconhece que elas existem que pode se responsabilizar por elas (GRIGOLETTO, 2011, p. 99).

A implicação de quem escreve com o saber, posicionando-se com relação às leituras que mobiliza, requer certa autonomia. É necessário que quem escreva saia da área de conforto, para assumir uma posição de autoria, responsabilizando-se por aquilo que escreve, ousando e criando novas configurações desse saber. Essa prática não é tarefa fácil, porque ao passar pelo ensino fundamental e médio, antes de chegar à universidade, os alunos não são levados a produzir uma escrita singular.

\section{MATERIAIS E MÉTODOS}

Esta pesquisa caracteriza-se como qualitativa e indiciária. A Pesquisa Qualitativa tem grande importância para investigações em contextos educacionais. De acordo com Esteban (2010, p. 127), esta abordagem é:

\footnotetext{
Uma atividade sistemática orientada à compreensão em profundidade de fenômenos educativos e sociais, à transformação de práticas e cenários socioeducativos, à tomada de decisões e, também ao descobrimento e desenvolvimento de um corpus organizado de conhecimentos.
}

Pesquisadores que optam por uma abordagem qualitativa focam sua atenção na descrição detalhada de situações, eventos, pessoas, interações e comportamentos observáveis e incorpora a voz dos participantes, suas 
experiências, atitudes, crenças, pensamentos e reflexões, tal e qual são expressas pelos participantes (SERRANO, 1994 apud ESTEBAN, 2010). A pesquisa qualitativa tem a característica da reflexibilidade, o que significa para Esteban (2014):

\footnotetext{
[...] dar especial atenção à forma que diferentes elementos linguísticos, sociais, culturais, políticos e teóricos influem de maneira conjunta no processo de desenvolvimento do conhecimento (interpretação na linguagem e na narrativa) (formas de apresentação) e impregnam a produção dos textos (autoridade e legitimidade) (ESTEBAN, 2014, p. 130).
}

Este estudo serve-se dessa característica a partir da abordagem qualitativa, porque se configura como uma prática interpretativa e, também, como um espaço de discussão, ao centralizar a atenção do pesquisador nas particularidades que compõem o objeto de estudo, a produção escrita de estudantes de engenharia Agronômica.

Por se tratar de um estudo que visa à investigar a produção escrita no ensino superior, na produção do conhecimento, buscamos um método que possibilitasse a análise a partir de um olhar acerca da singularidade dessas produções. Por isso, unem-se, nessa pesquisa, o qualitativo e o paradigma indiciário.

O paradigma indiciário, modelo epistemológico, proposto pelo historiador Ginzburg (1986), baseou-se nos detalhes, no resíduo, no episódico, no singular, ou seja, nos indícios, e leva o pesquisador a empreender a busca pela compreensão do fenômeno que deseja investigar. Portanto, ao assumirmos o paradigma indiciário para embasar as análises, buscamos pistas, indícios (signos verbais), identificando sinais imperceptíveis ou perceptíveis que essas produções escritas podem nos mostrar acerca da produção do conhecimento.

A composição do Corpus se deu, a partir da leitura de nove Relatórios de aula prática, produções advindas da disciplina de Microbiologia Geral do $2^{\circ}$ período do curso de Engenharia Agronômica da IES Particular. Ao proceder a leitura, optamos por analisar dois, tendo como critério de seleção aqueles que apresentavam a estrutura completa como introdução, desenvolvimento e 
conclusão. Para proceder a análise, decidimos mencionar essas produções com as Siglas RAP1 (primeiro relatório) e RAP2 (segundo relatório).

Os Relatórios de Aulas Práticas, cuja análise é compartilhada a seguir, são produções provenientes de uma aula prática da disciplina de Microbiologia Geral do segundo período do curso de Engenharia Agronômica, em uma IES privada do estado de Minas Gerais. Nessa aula, os alunos tiveram contato com os materiais e equipamentos necessários para a execução de procedimentos no laboratório. Para a produção escrita $R A P 1$ e $R A P 2$, as instruções realizadas pelo professor da disciplina eram: produzir o relatório, seguindo as normas da ABNT, porém, dentro dos padrões e formatos solicitados na aula, ou seja, elaborar uma breve introdução, escrever o resumo sobre o assunto tratado; seguido do desenvolvimento, descrevendo os procedimentos e técnicas utilizadas na aula prática, valendo-se de desenhos dos materiais e equipamentos utilizados. Finalizar com a conclusão e disponibilizar as referências.

\section{ANÁLISE DOS RELATÓRIOS DE AULAS PRÁTICAS DE MICROBIOLOGIA E RESULTADOS}

Análise RAP1: Influência dos fatores físicos sobre a atividade dos microrganismos - Introdução

(1) Bico de Bunsen e especificamente um simples objeto queimador de gás de pequeno porte onde pode se ajustar a quantidade ideal de chama que você precisa, ele recebeu esse nome em homenagem ao químico alemão chamado Robert Bunsen (RAP1).

"Basicamente, um bico de Bunsen é um queimador de gás de pequeno porte com uma chama ajustável, onde pode-se manipular a quantidade de gás e ar. O queimador recebeu este nome em homenagem a Robert Wilhelm Bunsen, químico alemão [...]" (MARTINEZ, 2015).

Os discentes se apropriam do texto disponível na internet, sem citar a fonte, embora façam menção nas referências incorretamente, uma vez que citam apenas o site. Nesse caso, não se trata de um exercício de paráfrase, 
porque não cita o texto fonte, não dá crédito a quem o escreveu, trata-se de plágio.

Os discentes não se comprometem com a construção do seu texto, constroem o parágrafo com trechos publicados em sites da internet, realizando algumas alterações como em: "Bico de Bunsen e especificamente um simples objeto queimador de gás de pequeno porte" (RAP1); "Basicamente, um bico de Bunsen é um queimador de gás de pequeno porte" (MARTINEZ, 2015). Substituem "basicamente" por "especificamente". Alteram também "é um queimador de gás de pequeno porte" por "um simples objeto queimador de gás de pequeno porte' (RAP1). Nest e caso, ao acrescentar o adjetivo "simples", atribuem uma característica e, de certa forma, depreciativa, pois o significado desse adjetivo, de acordo com Ferreira (2010, p. 700), "é algo sem dificuldade ou complexidade, algo simplório".

Os discentes se apropriam do texto disponível na internet, sem citar a fonte, fazendo pequenas alterações. Por meio dessa prática, de acordo com Barzotto (2016, p.131), "recolhe trechos que podem se tornar seus, ou criar uma aparência de que o que estão escrevendo é de usa autoria". Nessa mesma direção, Lima e Amorim (2014, p. 167) comentam a prática do Control+c Control+v, ressaltando que o estudante "utiliza as palavras ou as ideias de outrem sem fazer as devidas referências, o autor do dizer é silenciado":

(2) Autoclave é um objeto muito utilizado para a esterilização através de calor húmido, elas são basicamente constituídas por uma câmera em aço inox contendo válvulas de segurança, manômetro de pressão e um indicador de temperatura (RAP1)

Identificamos o texto fonte no site Boas Práticas (2013):

"As autoclaves utilizadas para esterilização por calor úmido constituemse basicamente de uma câmera em aço inox, com uma ou duas portas, possuem válvula de segurança, manômetros de pressão e um indicador de temperatura" (BOAS PRÁTICAS, 2013). 
Ocorre o procedimento de escrita mencionado por Fabiano (2014), no qual os discentes alteram algumas palavras para tentar afastar-se do texto fonte, porém não conseguem.

Se comparamos os dois textos, o do aluno e o do site Boas Práticas, as alterações são mínimas, mas dão indícios de que os discentes, ao fazê-las, têm a noção de que não podem copiar na íntegra, mas não percebem que essas alterações não fazem do discurso de outrem o seu. Na perspectiva Bakhtiniana, o sujeito se constitui pelo reconhecimento do outro em seu discurso. E isso não acontece nessas produções.

Em "Autoclave é um objeto muito utilizado para a esterilização através de calor húmido [...]", o estudante que produz o texto RAP1 tenta diferenciar-se de "as autoclaves utilizadas para esterilização por calor úmido [...]". Comparando essa escrita com a do texto fonte, observamos que o discente, com o intuito de alterá-lo, usa a palavra 'autoclave' no singular, enquanto o texto fonte se refere a este equipamento com o sintagma nominal 'As autoclaves', no plural. O estudante escreve "é um objeto muito utilizado", enquanto no texto fonte está "utilizadas". Já em "para a esterilização" acrescentam o artigo 'a', não encontrado no texto fonte "para esterilização". Alteram igualmente a preposição 'por', utilizada no texto fonte, pelo advérbio 'através', seguido da preposição 'de'. A mesma estratégia também é verificada em:

3) Elas são basicamente constituídas por uma câmara em aço inox contendo válvulas de segurança, manômetro de pressão e um indicador de temperatura (RAP1).

No texto fonte:

"Constituem-se basicamente de uma câmara em aço inox, com uma ou duas portas, possuem válvula de segurança, manômetros de pressão e um indicador de temperatura" (BOAS PRÁTICAS, 2013).

Quando comparados, os dois textos anteriores apresentam poucas alterações, indicando mais uma vez que os discentes têm noção de que não podem copiar os conceitos na íntegra, entretanto essas alterações não permitem que se apropriem do discurso de outrem como se fossem seu. $\mathrm{Na}$ 
perspectiva bakhtiniana, é necessário reconhecer que a presença do outro interfere no discurso desse sujeito, pois ele não se constitui discursivamente sozinho, mas pela possibilidade de interação entre um eu (sujeito dizente) e o outro.

Em outro trecho, o discente escreve:

(4) Estufa de esterilização e responsável pelo procedimento que elimina os microrganismos presentes nos instrumentos que utiliza a técnica do calor seco que oxida os microrganismos presentes nos instrumentos que utiliza a técnica do calor seco que oxida os microrganismos (RAP1).

Ao compararmos o texto acima do RAP1 com o texto fonte:

"A Estufa de Laboratório é responsável pelo procedimento que elimina os microrganismos presentes nos instrumentos. Um dos tipos de Estufa para esterilização e secagem é a que utiliza a técnica do calor seco, que oxida os microrganismos" (SPLABOR, 2013).

Novamente notamos que foram realizadas alterações, mas que comprometem o sentido do enunciado, deixando-o incoerente e inteligível. No texto original, a estufa de laboratório é responsável pelo procedimento que elimina os microrganismos presentes nos instrumentos. É considerada como um dos tipos de estufa para esterilização e secagem, ao utilizar a técnica do calor seco para oxidar os microrganismos. No texto do RAP1, lemos que a estufa de esterilização é responsável pela eliminação dos microrganismos presentes nos instrumentos, e que estes utilizam a técnica do calor seco que oxida os microrganismos, ou seja, ao invés de afirmar que a estufa utiliza o calor seco para eliminar os microrganismos, se afirma que os instrumentos utilizam a técnica, o que torna o texto confuso.. Além disso, a repetição, presentes nos instrumentos que utiliza a técnica do calor seco que oxida os microrganismos, compromete a inteligibilidade do texto. Ao misturar o discurso do texto fonte, o estudante confunde a si e ao leitor. O enunciado dá a entender que os instrumentos utilizam a técnica do calor seco, e não a estufa, comprometendo o sentido original do texto fonte. 
Analisamos a seguir partes do Relatório de Aula Prática 2, RAP2.

(1) O método mais empregado para matar microrganismos é o calor, por agir melhor sobre eles, e ser mais acessível, pois os microrganismos são considerados mortos quando perdem a capacidade de se multiplicar, e com o calor úmido a esterilização tem temperaturas acima de fervura da água $\left(120^{\circ}\right)$. (RAP2)

O texto fonte está publicado no site Coladaweb.com, escrito por Teixeira (c2015):

"O método mais empregado para matar microrganismos é o calor, por ser eficaz, barato e prático. Os microrganismos são considerados mortos quando perdem a capacidade de multiplicar" (TEIXEIRA, c2015).

No trecho do RAP2: "O método mais empregado para matar microrganismos é o calor, por agir melhor sobre eles, e ser mais acessível, pois os microrganismos são considerados mortos quando perdem a capacidade de se multiplicar", o discente faz uma pequena modificação no texto de Teixeira (c2015), alterando: "ser eficaz, barato e prático", do texto fonte por "agir melhor sobre eles, e ser mais acessível”, e acrescenta a conjunção explicativa 'pois', para emendar com o restante da fala do autor "Os microrganismos são considerados mortos quando perdem a capacidade de multiplicar", que é idêntica à de Teixeira (c2015).

Essa prática é chamada por Fabiano (2014) de imitação alinhada aos autores da área nos textos dos alunos; sobre isso a autora afirma que:

\footnotetext{
Os alunos ao produzirem seus textos, muitas vezes não remetem ao texto fonte pesquisado, não fazem menção ao nome do autor e nem utilizam o termo apud para dizer a fonte a qual se referem. A ausência das citações e o fato de deixarem de citar a fonte desconsideram os autores que escrevem os textos. Os alunos passam a imagem de serem donos do dizer (FABIANO, 2014, p. 204).
}

Passando a falsa imagem de serem donos dos textos que copiam, demonstram a falta de produção da escrita. Essa reprodução constante do texto alheio, ora copiando, ora reescrevendo com pouquíssimas alterações encaixadas no texto, remete à discussão do texto de trabalho despedaçado 
proposta por Barzotto (2016), também conhecido como colcha de retalhos. O autor explica que:

É aquele trabalho em que o sujeito que escreve vai observando vários trabalhos e recolhendo dele trechos que pensa que poderiam ser seus, que podem ser assumidos e incorporados ao seu, para formar seu próprio texto. Mas quando alguém lê o texto apresentado como seu, percebe que suas partes não formam um todo, é composto de pedaços isolados, apenas justapostos (BARZOTTO, 2016, p. 126).

É o que ocorre com as produções escritas analisadas anteriormente, visto que os discentes vão recolhendo trechos para formar um todo, porém o que conseguem é apresentar pedaços isolados. Além disso, ao fazer alterações no texto fonte, o discente do RAP2, compromete seu sentido, como em:

e com o calor úmido a esterilização tem temperaturas acima de fervura da água $\left(120^{\circ}\right)[\ldots]^{\prime}$ (RAP2).

já no texto fonte, Teixeira (c2016), diz que "A esterilização empregando calor úmido requer temperaturas acima de fervura da água (120ํ)" . Nesse trecho o estudante ao escrever o RAP2, altera "tem" por "requer", mudando o sentido do enunciado. Continuando, o discente enuncia:

(2) 'e a sim conseguindo a autoclave que e o mecanismo de ação e desnaturação de proteínas, então em contato com o vapor e nestas condições o calor úmido matará a todos' (RAP2)

Teixeira (c2015) no texto fonte, escreveu:

Estas são conseguidas nas autoclaves, e este é o método preferencial de esterilização desde que o material ou substância a ser esterilizado não sofra mudanças pelo calor ou umidade. A esterilização é mais facilmente alcançada quando os organismos estão em contato direto como vapor, nestas condições o calor úmido matará todos os organismos (TEIXEIRA, c2015).

'Estas', no texto fonte, faz referência às altas temperaturas conseguidas com a utilização das autoclaves' para esterilização através do calor úmido em altas temperaturas. Esse processo de esterilização só será possível se o 
material ou substância a ser esterilizado não sofrer mudanças de calor ou umidade. A esterilização por meio das autoclaves é mais eficaz quando os organismos estão em contato direto com o vapor (calor úmido) que os matará. Quando o discente escreve "[...] e a sim conseguindo a autoclave que e o mecanismo de ação e desnaturação de proteínas, então em contato com 0 vapor e nestas condições o calor úmido matará a todos [...]", compromete o sentido do enunciado, além de cometer um erro gramatical de escrever 'e assim', por 'e a sim'. E o verbo ser em é por 'e', não consegue articular de forma coerente com o parágrafo (1).

O discente, ao alterar o texto fonte, não conseguiu expressar-se de maneira satisfatória, incorrendo em uma incoerência, cometendo erros de escrita que comprometem o sentido do texto e sua compreensão. Para Koch e Elias (2012, p. 193) "como princípio de interpretabilidade", um texto só é coerente se for passível de ser interpretado, se fizer sentido.

No trecho a seguir o aluno escreve:

Já no texto fonte encontramos:

\section{(3) Calor seco/incineração}

O calor seco é um método mais simples, mas eficaz que consiste em flambagem que e oxidar os materiais com a alça diretamente sobre o fogo. Incineração Ele incinera e oxida os materiais, e o forno para esterilizar as vidrarias, mais ficar alerta com o tempo e a temperatura (RAP2).

\section{Calor seco}

a) Flambagem: $\hat{E}$ um método simples, porém muito eficaz. Consiste em colocar a alça de platina diretamente sobre o fogo, oxidando todo o material até virar cinzas.

b) Incineração: Também é muito eficaz. Utilizado para incinerar diversos tipos de materiais, como papéis, materiais hospitalares, carcaças de animais etc. Também oxida todo o material até virar cinzas.

\section{c) Fornos:}

Normalmente é utilizado para esterilizar vidrarias. Deve-se atentar bem à relação tempo x temperatura (GONÇALVES, 2015).

Comparando a produção escrita do discente com a do texto fonte, identificamos um equívoco, pois une as três informações de esterilização por 
meio do calor seco (incineração, flambagem (que também faz parte da incineração), e o forno), no mesmo título 'Calor seco/incineração', como se tratasse apenas da incineração. Quando enuncia: 'O calor seco é um método mais simples, mas eficaz que consiste em flambagem que e oxidar os materiais com a alça diretamente sobre o fogo', faz referência ao Bico de Bunsen, inclusive com a ilustração, embora ela estivesse solta em seu texto. Porém, ao enunciar que o calor seco 'consiste em flambagem que e oxidar os materiais com a alça diretamente sobre o fogo', ele se equivoca, porque de acordo com Pelczar Júnior, Chan e Krieg (1997, p. 197) "calor seco ou ar quente em temperaturas suficientemente altas levam os microrganismos à morte". Isso, pode ocorrer, de acordo com os autores, a partir da incineração, das radiações ionizantes e não ionizantes, da filtração e da dessecação, ou seja, a flambagem é um dos processos de esterilização com o calor seco através do Bico de Bunsen.

O discente, além de interpretar de forma equivocada a informação de Gonçalves (2015), com relação ao calor seco, sequer a questiona, ou certificase de que se trata de uma informação confiável ou correta.

Podemos notar em todos os trechos analisados o que Barzotto (2016) denominou de pedaços isolados e ou justapostos. É aquele trabalho em que o sujeito que escreve vai observando vários trabalhos e recolhendo dele trechos que considera que poderiam ser seus, que podem ser assumidos e incorporados ao seu, para formar seu próprio texto. Mas quando alguém lê o texto apresentado como seu, percebe que suas partes não formam um todo, é composto de partes isoladas, apenas justapostas (BARZOTTO, 2016, p.126).

Os estudantes que produziram os relatórios fizeram isso, foram recolhendo trechos da internet para dar a impressão que escreveram, mas na verdade plagiaram, não se apropriaram do saber passado na aula prática e estudado nas teorias em sala de aula, somente fizeram do texto do outrem o seu. 


\section{CONSIDERAÇÕES FINAIS}

O que percebemos com a análise realizada é que os relatórios foram escritos a partir de trechos copiados da internet, ou seja, em todos eles, os discentes praticaram o "ctrl c" (copiar) e "ctrl v" (colar), mencionados por Lima e Amorim (2014, p. 167), demonstrando que os estudantes de engenharia não se comprometem com a própria escrita e a construção de conhecimentos sobre ela.

Houve nas produções RAP1 e RAP2, uma apropriação da fala do outro, com parágrafos soltos e descontextualizados. Mesmo com as estratégias empreendidas pelos discentes para diferenciar os trechos encontrados na internet dos seus, para não conferir crédito a quem é de direito, não conseguiram uma produção escrita coerente e que pudesse demonstrar algum conhecimento advindo da aula prática. A falta de articulação dos conhecimentos teóricos e práticos ficou evidente.

Essas produções evidenciaram uma escrita onde o apagamento do autor (aluno) deu-se em todo o texto, demonstrando um sujeito que parece não se comprometer com o próprio processo de construção de conhecimento. Destacamos também que a cópia se volta contra o próprio profissional em formação, pois ao não se posicionar frente ao saber, não se responsabilizando por aquilo que pronuncia, esse futuro engenheiro agronômico perde a oportunidade de desenvolver uma escrita que mobiliza, que considera a importância da negociação de sentidos, demonstrando uma percepção ingênua de que para tudo o que se tem a dizer existe de antemão uma expressão (palavra) pronta e disponível no contexto na internet.

O ctrl+c (copiar) e ctrl+v (colar), ou seja, o plágio observado nas produções (relatórios) não viabiliza a possibilidade de o aluno aprender como se faz, de identificar como funciona a ordem desse discurso, e de alguma forma (re)significá-lo, para construir conhecimento. 


\section{REFERÊNCIAS}

ALMEIDA, S. Escrita no ensino superior: a singularidade em monografias, dissertações e teses. São Paulo: Paulistana, 2011. Disponível em: http://doi.editoracubo.com.br/10.4322/978-85-99829-50-9. Acesso em: 15 jan. 2016.

BAKHTIN, M. M. Estética da criação verbal. 4. ed. São Paulo: Martins Fontes, 2003.

BAKHTIN, M. M. Marxismo e filosofia da linguagem: problemas fundamentais do método sociológico em ciência da linguagem. 11. ed. São Paulo: Hucitec, 2004.

BARZOTTO, V. H.; ALMEIDA, S. M. P. A pesquisa na universidade: uma questão de leitura. In: RIOLFI, C. R.; ALMEIDA, S.; BARZOTTO, V. H. (org.). Leitura e escrita: impasses na universidade. Campinas: Mercado de Letras, 2013. p. 73-89.

BAZZO, W. A.; PEREIRA, L. T. V. Introdução à engenharia: conceitos, ferramentas e comportamentos. 2. ed. Florianópolis: UFSC, 2009.

BARZOTTO, V. H. Leitura, escrita e relação com o conhecimento. Campinas: Mercado das Letras, 2016.

BOAS PRÁTICAS. Autoclaves e a esterilização por calor úmido. São Paulo: Boas Práticas, 2013. Disponível em:<http://boaspraticasnet.com.br/?p=4160>. Acesso em: 30 out. 2016.

BRASIL. Ministério da Educação. Secretaria de Educação Profissional e Tecnológica. Instituto Federal de Educação, Ciência e Tecnologia do Triângulo Mineiro - Campus Uberlândia. Projeto Pedagógico do Curso Bacharelado em Engenharia Agronômica. Uberlândia: IFTM, 2014. Disponível em: http://www.iftm.edu.br/SITES/uberlandia/cursos/EngAgronomica/docs/ppcenga gro.pdf. Acesso em: 25 jan. 2016.

ESTEBAN, M. P. S. Pesquisa qualitativa em educação: fundamentos e tradições. Porto Alegre: AMGH, 2010.

FABIANO, S. A prática da pesquisa na graduação como fio condutor da formação em letras. In: BARZOTO, V. H. Leitura, escrita e pesquisa em letras. São Paulo: Mercado das Letras, 2014.

FERREIRA, A. B. H. Dicionário da língua portuguesa. 8. ed. ver. atual. Curitiba: Positivo, 2010 
FUNDAÇÃO DE AMPARO À PESQUISA DO ESTADO DE SÃO PAULO. Código de boas práticas científicas. São Paulo: FAPESP, 2012. Disponível em:

https://www.unip.br/pesquisa/download/FAPESP Codigo de Boas Praticas C ientificas jun2012.pdf. Acesso em: 28 dez. 2016.

GALLI, F. C. S. Escrita: (Re) construção de vozes, sentidos, "eus". In: ECKERT-HOFT, B. M.; CORACINI, M. J. R. F. (Org.). Escrit(ur)a de si e alteridade no espaço papel-tela: alfabetização, formação de professores, línguas materna e estrangeira. Campinas: Mercado de Letras, 2010.

GINZBURG, C. Mitos, emblemas e sinais: morfologia e história. São Paulo: Companhia das Letras, 1986.

GONÇALVES, F. S. Métodos físicos de controle de microrganismos. InfoEscola. Navegando e Aprendendo. 2015. Disponível em: $<$ http://www.infoescola.com/microbiologia/metodos-fisicos-de-controle-demicroorganismos/>. Acesso em: 01 nov. 2016.

GRIGOLETTO, M. Lições do modelo: a escrita que engessa e mobiliza. In: RIOLFI, C. R.; ALMEIDA, S.; BARZOTTO, V. H. (org.). O inferno da escrita: produção escrita e psicanálise. Campinas: Mercado de Letras, 2011.

GRIGOLETTO, M. Do temor do texto ao texto próprio: desafios ao estudo da linguagem. ECKERT-HOFT, B. M.; CORACINI, M. J. R. F. (org.). Escrit(ur)a de si e alteridade no espaço papel-tela: alfabetização, formação de professores, línguas materna e estrangeira. Campinas: Mercado de Letras, 2013.

KOCH, I. V.; ELIAS. V. M. Ler e escrever: estratégias de produção textual. 2. ed. São Paulo: Contexto, 2012.

LIMA, M. H. A.; AMORIM, C. S. O ritual escolar do "ctrl+c" (copiar) e "ctrl+v" (colar): reflexões para o ensino da língua portuguesa. In: CAMPOS, S. F; BARZOTTO, V. H. (org.). Ensino da leitura e da escrita. Natal: UFRN, 2014. p. $167-193$

LODER, L. L. Engenheiro e professor, dois papéis em uma profissão: desafios e perspectivas na conciliação de identidades. In: CONGRESSO BRASILEIRO DE EDUCAÇÃO EM ENGENHARIA, 35., 2007, Curitiba. Anais... Curitiba: ABENGE, 2007. Disponível em:

$<$ http://www.abenge.org.br/CobengeAnteriores/2007/artigos/290-

Liane\%20Ludwig\%20Loder.pdf>. Acesso em: 20 jul. 2016.

MACHADO NETO, A. M. Do modelo ao estilo: possibilidades de autoria em contextos acadêmico-científicos. In: CALLIL, E. Trilhas de escrita: leitura e ensino. São Paulo: Cortez, 2007. p. 171-190. 
MARTINEZ, M. Bico de Bunsen.InfoEscola. Navegando e Aprendendo. 2015. Disponível em: <http://www.infoescola.com/materiais-de-laboratorio/bico-debunsen/>. Acesso em: 01 nov. 2016.

PELCZAR JÚNIOR, M. J.; CHAN, E. C. S.; KRIEG, N. R. Microbiologia: conceitos e aplicações: volume 1. 2. ed. São Paulo: Pearson Makron Books, 1997.

RIOLFI, C. R. Lições de coragem: o inferno da escrita. In: RIOLFI, C. R.; BARZOTTO, V. H. (org.). $O$ inferno da escrita: produção escrita e psicanálise. Campinas: Mercado de Letras, 2011.

SOUZA, D. M. Ideal de escrita e livro didático. In: CORACINI, M. J. R. F. (org.). Interpretação, autoria e legitimação do livro didático. Campinas: Pontes, 1999. p. $135-141$.

SPLABOR Equipamentos para Laboratório. Estufa de esterilização e secagem: eliminação de microrganismo através do calor. 2013. Disponível em:

$<$ http://www.splabor.com.br/blog/estufa-de-esterilizacao-e-secagem/estufas-deesterilizacao-e-secagem-eliminacao-de-microorganismo-atraves-do-calor/>. Acesso em: 29 de nov. 2016.

TEIXEIRA, F. Controle de microrganismos. Coladaweb. c2015. Disponível em:

$<$ http://www.coladaweb.com/biologia/saude/controle-dos-microorganismos >. Acesso em: 01 dez. 2016. 